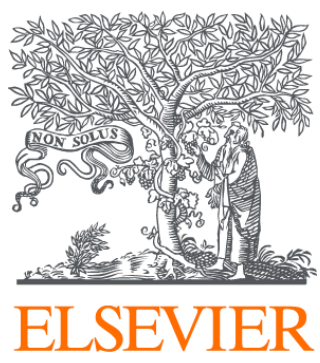

Since January 2020 Elsevier has created a COVID-19 resource centre with free information in English and Mandarin on the novel coronavirus COVID-

19. The COVID-19 resource centre is hosted on Elsevier Connect, the company's public news and information website.

Elsevier hereby grants permission to make all its COVID-19-related research that is available on the COVID-19 resource centre - including this research content - immediately available in PubMed Central and other publicly funded repositories, such as the WHO COVID database with rights for unrestricted research re-use and analyses in any form or by any means with acknowledgement of the original source. These permissions are granted for free by Elsevier for as long as the COVID-19 resource centre remains active. 


\title{
Challenges in the Practice of Sexual Medicine in the Time of COVID-19 in Portugal
}

\author{
Joana Carvalho, PhD, ${ }^{1,2}$ and Patrícia M. Pascoal, PhD 1,3,4
}

The worldwide impact of COVID-19 has reached all spheres of human functioning. Such impact on social, relationship, and individual spheres has posed strong challenges within all scientific areas. Most branches of science, including those relating to human sexuality, are now called at providing new means on how to best deal with COVID-19. In this work, we will approach what we consider may be some of the core challenges emerging within the field of clinical sexology* during COVID-19. We will briefly discuss on issues regarding clinicians' professional demands, as well as on the social, relationship, and individual dimensions affecting different facets of human sexuality during COVID-19. We outline all these dimensions are interconnected, supporting a biopsychosocial approach in the management of COVID19-related sexual and relationship problems. We further acknowledge the current work mirrors our own experience as clinical sexologists in the Portuguese context. Accordingly, all arguments are open to debate. We expect the following topics may trigger a future debate on the role of sexual medicine, sex therapy, and sexual counseling, in times of crisis.

\section{PROFESSIONAL DEMANDS}

The recent scenario of pandemic has exposed several vulnerabilities within worldwide health-care and social systems, some of them including services concerning sexual health and human sexual rights. On the other hand, it also brought to light a remarkable social awareness on so many issues tapping into the scope of clinical sexology (eg, sexual and reproductive health, human sexual rights, relationships, and sexuality). In times of pandemic, the focus on sexuality-related issues is a notable sign of

Received May 19, 2020. Accepted May 19, 2020.

'Escola de Psicologia e Ciências da Vida, Universidade Lusófona de Humanidades e Tecnologias, Lisboa, Portugal;

2 HEl-Lab: Digital Human-Environment and Interactions Lab, Universidade Lusófona de Humanidades e Tecnologias, Lisboa, Portugal;

${ }^{3}$ CICPSI, Faculdade de Psicologia, Universidade de Lisboa, Lisboa, Portugal;

${ }^{4}$ CPUP, Faculdade de Psicologia e Ciências da Educação, Universidade de Porto, Porto, Portugal

Copyright (c) 2020, International Society for Sexual Medicine. Published by Elsevier Inc. All rights reserved. https://doi.org/10.1016/j.jsxm.2020.05.024

*We are using Clinical Sexology as an umbrella term aimed at including Sexual Medicine, Sex Therapy, Sexual Counseling in a clinical contex, or any clinical specialty working within the field of sexual health, namely with sexual problems. how services and science in sexuality are significant, even when survival issues are priority.

One of the major topics that was brought to the center of discussion was e-Health interventions, that is, the use of communication and information technologies for health (eg, SMS, e-mail, video call, apps, etc.). The World Health Organization followed by key professional societies such as the American Psychological Association deemed e-Health a priority target for the improvement of public and universal health. ${ }^{1}$ The need of universal health was made real for countless citizens who have never experienced a crisis with such a dimension as the current pandemic. The time of COVID-19 has required healthcare and social systems, clinicians, and citizens to adjust to the digital era in a matter of days.

e-Health interventions in clinical sexology have been promoted earlier. Even so, there is little evidence on how professionals and patients appraise such tools and whether these are effective. Indeed, before current pandemic, there was not an established baseline on how well professionals working in the fields of clinical sexology dealt with e-Health. COVID-19 seems to have triggered a research need that was forgotten in the clinical sexology context, with strong clinical implications, for example, treatment effectiveness, therapeutic adherence, competence to deliver e-Health interventions. Although the extension of the challenges imposed by e-Health can only be accurately measured after the COVID-19 crisis, we believe that ongoing clinical guidelines on clinical sexology should include specific standards in e-Health. Even further, these standards should carefully look at the ethical challenges tied to digital clinical interventions, and to what extent these challenges may eventually change across countries and health-care systems, or within the different branches working in the field of human sexuality. Ultimately, we must answer the question, how far is clinical sexology from universal health.

In addition, it is worth mentioning the effects of the pandemic on the working routines of sexual health professionals. Professionals working in the sexuality field, particularly those who exclusively depend on private practice, are possibly facing unstable economical situations. These professionals may further lack competence to provide e-Health services, as well as their usual network for referral and supervision. We are further aware some clinical sexology professionals were relocated to prioritize COVID-19 assistance, reducing sexual health services and assistance. In our view, key professional societies in the fields of sexual medicine, sex therapy, and sexual counseling may play a 
supportive role, delivering formative, guideline, and networking solutions (see Table 1 for a summary of recommendations).

\section{SOCIETAL DIMENSIONS}

Many of the topics discussed in the context of the societal consequences of COVID-19 emphasize the pandemic's deleterious effects in women. The United Nations acknowledged that sexual and reproductive health care is particularly at risk during the crisis, leaving women exposed to increased vulnerability. ${ }^{2}$ In Portugal, despite the maintenance of health care concerning sexual and reproductive issues, professionals have detected a significant decrease of women attending obstetrician and gynecology emergency services. These women were known to use these services as the first line to report partner's physical violence or sexual abuse. We are thus aware of an undetected proportion of women at high risk of (sexual) victimization. These women have been unintentionally neglected by the system, and this may last for the entire lockdown. While physical and sexual abuse are themes continuously under debate, we must acknowledge that lockdown situations require additional measures that were not previously designed. In a similar vein, gender inequalities regarding working place have been under social debate. Given lockdown, families are now combining domestic tasks, including their children's school needs, with teleworking. Such scenario is believed to maximize the deleterious effects of COVID-19 in women as well. In all, the effects of pandemics extend well beyond survival issues, reaching fundamental human rights, including sexual rights, which we must consider before next lockdowns. In line with the World Association for Sexual Health resolutions on human sexual rights in the context of COVID- $19,{ }^{3}$ it seems undeniable that professionals working within the diverse branches of human sexuality help to preserve fundamental aspects on human sexual rights, including gender equality, in times of pandemics.

\section{RELATIONSHIP DIMENSIONS}

Contextual changes have a marked impact on relationships, causing crises and imbalance, but also improvement opportunities. The ability to adapt is a key feature characterizing high-level satisfaction and marital quality relationships. Partners' sexuality is expected to be impacted by adaptation demands, as sexual satisfaction and functioning largely depends on relationship dynamics that might be at risk during crises. Conversely, such dynamics are also impacted by sexual functioning outcomes. Indeed, sexuality plays a determining role in maintaining relationships. In the current adaptation scenario, professionals are called at performing a close inspection of relationship factors, as these may overshadow sexual concerns.

Within this context, is worth noting that the COVID-19 lockdown has shaped new relationship configurations. People in a loving relationship of commitment are going through lay off, unemployment, telework, and so forth, and this may apply to one or both partners. Furthermore, most partners are likely combining professional, parenthood, and caregiving demands, assuming new roles within their relationship dynamics. Professionals in sexual medicine, sex therapy, and sexual counseling must now shape their assessment and intervention tools as to fit the new relationship constellations and further consider the mental health impact of such reality. We must be especially attentive to the exacerbation of pre-existing symptomatology, as well as emerging difficulties, which may feel unexpected for the couple. The new daily stressors (eg, parenthood demands, reorganization of family subsystems, reduced incomes) should be evaluated as their management can deem both romantic and sexual needs to a secondary role. ${ }^{4}$ Such stressors may further have a differentiated impact in partners, increasing feelings of distressful sexual desire discrepancy, ${ }^{5}$ diminishing important contextual and emotional triggers for the experience of sexual arousal, ${ }^{6}$ or lowering the ludic elements that are associated with sexual satisfaction, ${ }^{7}$ whether we are dealing with same-gender or gender-diverse relationships. Within this regard, is worth mentioning that emotional expression, sexual self-disclosure, and intimacy are important predictors of sexual satisfaction and may need to be optimized. ${ }^{8,9}$

In addition, many people in dating relationships who have decided to cohabit, or even get married, were caught in the context of the pandemic. These individuals may experience some ambiguity regarding the meaning of their decision, and must now deal with defrauded expectations, which may further prompt new areas of relationship tension. Similarly, people in consensual nonmonogamous relationships may have to struggle to find cohabitation solutions that are equitable for the different relationships they are involved with and may have to do options that deprive them from living in full their relationship orientation. Professionals cannot neglect this aspect as well. All these relationship dynamics may challenge sexual medicine professionals to refer patients to couple therapists with training in sexology.

\section{INDIVIDUAL DIMENSIONS}

\section{Risky Behavior and Sexual Violence}

COVID-19 has further launched a massive discussion on how individuals deal with the emotional states prompted by lockdown and social isolation. This too is expected to impact individuals' sexual health and functioning, as we are aware of the role of emotional states in human sexual response and behavior. Low positive effect and depressive mood were particularly linked to sexual difficulties and dysfunction. ${ }^{10}$ However, this is a challenging relationship, as in some of the cases, negative mood actually trigger sexual response, including sexual desire and arousal, ${ }^{11}$ or masturbation. ${ }^{12}$ Even further, individuals were found to tune attention toward sexual contents under sad mood, which may be regarded as an adaptive behavior aimed at ensuring reproduction or the maintenance of affective bonds, even in the presence of negative events. ${ }^{13}$ On the other hand, increased 
Table 1. Summary of recommendations in the context of COVID-19 (expert opinion)

\begin{tabular}{ll}
\hline Area to be approached & Recommendations \\
\hline Professional demands & $\begin{array}{c}\text { To establish a baseline evaluation of e-Heath protocols implemented in sexual medicine, sex therapy, and } \\
\text { sexual counseling } \\
\text { To establish guidelines, including ethical standards, for e-Health interventions } \\
\text { To provide formative and networking possibilities aimed at developing e-Health } \\
\text { To promote gender equality and facilitate access to people at risk of sexual victimization, discrimination, or } \\
\text { any form of social exclusion based on gender or sexual orientation }\end{array}$ \\
Societal dimensions & $\begin{array}{c}\text { To consider new family configurations and specific stressors resulting from COVID-19 (eg, unemployment, } \\
\text { domestic overload, endorsement of new roles within the family system) } \\
\text { To consider and normalize partners' expectations about relationships' dynamics during crisis, including } \\
\text { discrepancies in sexual desire or any form of sexual expression }\end{array}$ \\
$\begin{array}{c}\text { To consider lack of privacy, forced separation of intimate partners, absence of usual erotic cues, or lack of } \\
\text { partner }\end{array}$ \\
$\begin{array}{c}\text { To consider intimate abusive relationships } \\
\text { To consider the comorbidity between mental health problems (eg, depressive states) and sexual } \\
\text { dysfunction and differentiate sexual complaints from sexual symptoms emerging within primary } \\
\text { psychopathological conditions due to COVID-19 } \\
\text { To consider cognitive distraction during sexual activity with a special focus on body image issues, } \\
\text { contamination worries, or any theme resulting from the current scenario (eg, unemployment, } \\
\text { uncertainty regarding the future) } \\
\begin{array}{c}\text { To consider the interplay role between emotional regulation, dysfunctional coping mechanisms (eg, alcohol } \\
\text { consumption, out of control pornography consumption), and risky sexual behaviors or violence }\end{array}\end{array}$ \\
\hline
\end{tabular}

sexual desire and arousal during negative affective states have been regarded as a coping mechanism; individuals are believed to use sex as means to cope with dysfunctional mood. ${ }^{14}$ Furthermore, and to our concern, such dynamic has been linked to risky sex and may underpin hypersexuality-like conditions. ${ }^{15}$ This scenario has been under informal debate as we recognized that COVID-19, lockdown, and the social isolation measures might trigger maladjusted sexual behavior by prompting dysfunctional mood states. Indeed, boredom has been posit as a potential trigger of hypersexuality-like behaviors (eg, high frequency of pornography consumption and cybersex) and was found among the psychological features of sexual addicts. ${ }^{16}$ Online sexual activities are thus believed to be used to manage boredom. ${ }^{16}$ Accordingly, one special challenge that emerged in the current pandemic was to manage the expected increase in symptom severity within hypersexuality-like conditions. Increasing the monitoring of symptoms and maladaptive emotional states using communication and information technology tools may be used as an option, although we can only discuss its efficacy in the long term. Similarly, sexually offending behavior may be triggered by negative emotional states. ${ }^{17}$ In addition, boredom, stress, or anxiety was shown to increase deviant sexual fantasies in adult and child sexual offenders. ${ }^{18,19}$ In the current lockdown, this is of course worrisome. We speculate a high chance of sexual victimization, particularly within intimate relationships. This may be also true regarding intrafamiliar sexual abuse of minors, as children are now confined with offenders. Is worth noting that in Portugal, sexual offenders are not tracked after release. Also, despite the absence of official statistics at the moment in Portugal, a great focus on sexting behaviors (particularly performed by adolescents), as well as on child pornography incitement, has been reported. Such scenario poses us the challenge on how to best address sexual education and prevention of sexual abuse, bearing in mind that lockdown and physical isolation may prompt risky behaviors.

\section{Sexual Difficulties and Functioning}

Psychological distress triggered by COVID-19 varies as a function of people's exposure (ie, contaminated, exposed, in isolation, or not isolated) and is associated with perceived individual risk and beliefs about the disease. ${ }^{20}$ Psychological distress in this specific scenario must be accounted by sexual health professionals, given the strong comorbidity between emotional disorders and sexual dysfunction. ${ }^{21}$ Clinicians must disentangle whether sexual complaints such as low sexual desire emerge within dyadic processes or, instead, if they result from other psychopathology conditions such as depression, anxiety, or even posttraumatic stress disorder. Such distinction will likely determine the course of treatment. Likewise, psychological distress can make it challenging to enjoy erotic experiences, either because of diffculties in letting go and enjoying the experience or because of problems in personal and interpersonal emotional regulation, increasing the chance of marital conflict. Still within this regard, we highlight the role of body dissatisfaction in sexual functioning. Body image dissatisfaction is impacted by emotional ingestion, which is a dysfunctional coping strategy aimed at dealing with negative emotional states. Emotional ingestion may be maximized by lockdown and COVID-19-associated distress. Within this context, it has been recognized that individuals endorsing an inflexible pattern of body image beliefs are expected to increase 
cognitive distraction during sexual activity, and a phenomenon known as spectatoring, associated with sexual difficulties and dysfunction.

\section{Final Note}

Although the social and health impacts of COVID-19 are under study throughout the globe, only at the end of the pandemic we may have a clear and empirically supported view of the major challenges and best approaches emerging from COVID-19. In line with this trend, we are aware of the many attempts to research the impact of COVID-19 in all spheres of sexuality. Fortunately, such attempts will eventually translate into a progress within the fields of sexual medicine, sex therapy, and sexual counseling. We hope we will be able to deliver better practices for times of crisis, and above all, to ensure human sexual rights despite adversity.

Corresponding Author: Joana Carvalho, Universidade Lusófona, Campo Grande 376, 1749-024 Lisboa, Portugal. Tel: 217515 500, Fax: 217577 006; E-mail: joana.pereira.carvalho@gmail.com

Conflict of Interest: The authors report no conflicts of interest.

Funding: None.

\section{STATEMENT OF AUTHORSHIP}

\section{Category 1}

(a) Conception and Design

Joana Carvalho, Patrícia M. Pascoal

\section{Category 2}

(a) Drafting the Article Joana Carvalho, Patrícia M. Pascoal

(b) Revising It for Intellectual Content Joana Carvalho, Patrícia M. Pascoal

\section{Category 3}

(a) Final Approval of the Completed Article Joana Carvalho, Patrícia Pascoal

\section{REFERENCES}

1. World Health Assembly. Digital Health. https://www.who.int/ ehealth/about/en/. Accessed April, 20, 2020.

2. Endler M, Al Haidari T, Chowdhury S, et al. Danielsson KG - for the FIGO Committee for Human Rights, Refugees and Violence Against Women. Sexual and reproductive health and rights of refugee and migrant women: gynecologists' and obstetricians' responsibilities. Int J Of Gynecol Obstet 2020;149:113-119.

3. World Association for Sexual Health. Sexual rights in the context of the global COVID-19 crisis. https://worldsexualhealth.net/sexualrights-in-the-context-of-the-global-covid-19-crisis/. Accessed April, 20, 2020.
4. Bodenmann G, Atkins DC, Schär M, et al. The association between daily stress and sexual activity. J Fam Psychol 2010; 24:271-279.

5. Dewitte M, Carvalho J, Corona G, et al. Sexual desire discrepancy: A Position Statement of the European Society for Sexual Medicine. Sexual Medicine 2020;8:121-131.

6. Laan E, Both S. What makes women experience desire? Feminism Psychol 2008;18:505-514.

7. Calvillo C, Sánchez-Fuentes DM, Sierra CJ. An Explanatory Model of Sexual Satisfaction in Adults with a Same-Sex Partner: An Analysis Based on Gender Differences. Int J Environ Res Public Health 2020;17:3393.

8. Pascoal PM, Lopes CR, Rosa PJ. The mediating role of sexua self-disclosure satisfaction in the association between expression of feelings and sexual satisfaction in heterosexual adults. Revista Latinoamericana de Psicología 2019;51:74-82.

9. Pascoal PM, Narciso I, Pereira NM. Emotional intimacy is the best predictor of sexual satisfaction of men and women with sexual arousal problems. Int J Impotence Res 2013;25:51-55.

10. Nobre PJ, Pinto-Gouveia J. Emotions during sexual activity: Differences between sexually functional and dysfunctional men and women. Arch Sex Behav 2006;35:8-15.

11. Lykins $A D$, Janssen $E$, Graham CA. The relationship between negative mood and sexuality in heterosexual college women and men. J Sex Res 2006;43:136-143.

12. Cyranowski JM, Bromberger J, Youk A, et al. Lifetime depression history and sexual function in women at midlife. Arch Sex Behav 2004;33:539-548.

13. Carvalho J, Pereira R, Barreto D, et al. The effects of positive versus negative mood states on attentional processes during exposure to erotica. Arch Sex Behav 2017;46:2495-2504.

14. Bancroft J, Janssen E, Strong D, et al. Sexual risk-taking in gay men: The relevance of sexual arousability, mood, and sensation seeking. Arch Sex Behav 2003;32:555-572.

15. Bancroft J, Vukadinovic Z. Sexual addiction, sexual compulsivity, sexual impulsivity, or what? J Sex Res 2004;41:225-234.

16. de Oliveira L, Carvalho J. The link between boredom and hypersexuality: A systematic review. J Sex Med press.

17. Ward T, Beech A. An integrated theory of sexual offending. Aggression Violent Behav 2006;11:44-63.

18. McKibben A, Proulx J, Lusignan R. Relationships between conflict, affect, and deviant sexual behaviors in rapists and child molesters. Behav Res Ther 1994;32:571-575.

19. Swaffer T, Hollin C, Beech A, et al. An exploration of child sexual abuser's fantasies before and after treatment. Sexual Abuse. A J Res Treat 2000;12:61-68.

20. Zhang J, Lu H, Zeng H, et al. The differential psychological distress of populations affected by the COVID-19 pandemic. Brain Behav Immun 2020.

21. Forbes MK, Baillie AJ, Eaton NR, et al. A Place for Sexual Dysfunctions in an Empirical Taxonomy of Psychopathology. J Sex Res 2017;54:465-485. 